\title{
Management of cardiopulmonary arrest in an educational video: contributions to education in pediatric nursing*
}

\author{
Gabriel Zanin Sanguino $0^{1,2}$ \\ (iD) https://orcid.org/0000-0002-3273-5496 \\ Maria Cândida de Carvalho Furtado ${ }^{1}$ \\ (D) https://orcid.org/0000-0001-7942-4110 \\ Simone de Godoy ${ }^{1}$ \\ (D) https://orcid.org/0000-0003-0020-7645 \\ Jéssica Batistela Vicente ${ }^{1}$ \\ (D) https://orcid.org/0000-0002-7134-9213 \\ Jacqueline Rodrigues da Silva ${ }^{1}$ \\ (D) https://orcid.org/0000-0001-8886-2980
}

\footnotetext{
This article refers to the call "Educational technologies and innovative teaching methods in the training of human resources in health". Paper extracted from master's thesis "Development of na educational material for handling pediatric cardiorespiratory arrest caused by respiratory failure", presented to Universidade de São Paulo, Escola de Enfermagem de Ribeirão Preto, PAHO/WHO Collaborating Centre for Nursing Research Development, Ribeirão Preto, $\mathrm{SP}$, Brazil.

1 Universidade de São Paulo, Escola de Enfermagem de Ribeirão Preto, PAHO/WHO Collaborating Centre for Nursing Research Development, Ribeirão Preto, SP, Brazil.

2 Scholarship holder at the Conselho Nacional de Desenvolvimento Científico e Tecnológico (CNPq), Brazil.
}

\begin{abstract}
Objective: to make and validate an educational video about the management of pediatric cardiopulmonary arrest caused by respiratory failure. Method: methodological study developed in three stages: preparation and validation of a clinical case; production; and validation of educational video. To build the educational video, the Fleming, Reynolds and Wallace methodological framework was used. Results: the clinical case was validated by ten expert referees, who worked as nurses in different regions in Brazil, by completing an online form, with one round of evaluation and calculation of the content validity index. The educational video was validated by three expert judges and 25 nursing students in an evaluation round and contains six scenes, with duration of nine minutes and 56 seconds. An agreement over $80 \%$ was reached for most of the items in both the clinical case and the educational video. Conclusion: the educational video proved valid regarding face and content. This educational technology has the potential to meet the demands of students, who are digital natives, related to teaching of management of pediatric cardiopulmonary arrest caused by respiratory failure.
\end{abstract}

Descriptors: Instructional Films and Videos; Educational Technology; Nursing Education; Heart Arrest; Respiratory Insufficiency; Pediatrics.

\section{How to cite this article}

Sanguino GZ, Furtado MCC, Godoy S, Vicente JB, Silva JR. Management of cardiopulmonary arrest in an educational video: contributions to education in pediatric nursing. Rev. Latino-Am. Enfermagem. 2021;29:e3410. [Access f f - i]; Available in: DOI: http://dx.doi.org/10.1590/1518-8345.3680.3410. 


\section{Introduction}

Cardiopulmonary arrest (CPA) is a phenomenon described as the abrupt cessation of circulatory, respiratory, and cerebral activities, which directly interferes with blood circulation and efficacy of the pulmonary system to promote gas exchanges ${ }^{(1)}$.

In pediatrics, the main causes of CPA are shock and respiratory failure. This is defined as the respiratory system's incapacity to keep its normal functions and effectively carry out the gas exchange mechanism ${ }^{(2)}$.

When the management of pediatric cardiopulmonary resuscitation is considered, preparation and technical and scientific knowledge of nurses is important to reverse the clinical condition shown and help patients get a better prognosis in this emergency situation ${ }^{(3)}$.

This preparation can be offered during training of these professionals over undergraduate courses. However, it is understood that it is necessary to take into account the students' profile so the learning process is appealing and leads to the acquisition of the knowledge they are intended to have. There is widespread availability of contents on the internet, and authors identified that undergraduate students access knowledge by means of different learning methods, especially those involving technological resources, and have decreasing interest in classes given the traditional way ${ }^{(4)}$. Born in an era of great availability and access to digital media, these students are known as digital natives ${ }^{(5)}$.

The change in the profile of undergraduate students calls for the urgent development of educational materials that provide students with autonomy and raise their interest during the teaching-learning process so they can receive training that qualifies them for the job market, reduces the number of dropouts and gives the students who get a degree the possibility of developing their professional activities actively in face of the needs of the society to which they belong(6).

To design the education of this population and follow technological progress, the universities' teaching staff must use active and innovative methodologies so students can build their knowledge and feel like participating in teaching activities ${ }^{(7)}$.

The use of different active teaching approaches and methodologies has become an increasingly present and necessary practice in the nursing training sphere, especially those that incorporate technologies for the development of educational materials ${ }^{(7)}$.

Educational videos have stood out in the nursing field among the educational tools and methodologies that offer innovative and technological resources to allow students to learn. They are considered a low-cost, easily accessible educational technology that offers immediate behavioral changes $^{(8)}$.
The development of educational videos relies on designing a material with a pedagogical basis and purpose. This material must also be validated to guarantee that its objectives are achieved( ${ }^{(9)}$.

Because of the relevance of a meaningful learning, in which students are the main axis, that results in timely and proper care to children in critical health situation, the objective of the present study was to make and validate an educational video about the management of pediatric CPA caused by respiratory failure.

\section{Method}

This was a methodological study whose data collection occurred between March and October 2018. It had three steps: elaboration and validation of a clinical case, making of an educational video, and evaluation of this video.

The methodological framework proposed by Fleming, Reynolds, and Wallace ${ }^{(10)}$ was applied to the making of the video.

The first step consisted of elaborating and validating a clinical case. It was developed based on experiences of the authors, clinical nurses and professors in the areas of pediatric nursing and development of educational technologies. Eleven expert referees were invited to participate in the evaluation of the video, and ten replied. Selection and inclusion of these professionals were carried out after analysis of their curriculum, available on the Lattes Platform. The search criteria used were being a nurse and filling out an adapted script ${ }^{(11)}$ that was designed to collect information on academic titles, clinical practice time, publications in the field, and participation in scientific events.

The second step referred to the making of the educational video, which was executed having the clinical case as a starting point. For the video evaluation, three expert referees and 59 students enrolled in a nursing undergraduate course at public higher education institution were invited. These students validated the video during their participation in an extension course offered by the authors. The inclusion criteria were being a nursing undergraduate student enrolled from the third semester of the course onward and fully filling out the study forms online. The students who did not meet the latter criterion were excluded. Twenty-five students completed the extension course.

The making of the video had three steps: preproduction, production, and post-production ${ }^{(10)}$.

During pre-production, a clinical case about pediatric CPA caused by respiratory failure was elaborated and validated. Subsequently, the expert referees received an on-line form, via Google Forms, containing free and 
informed consent forms and a characterization section whose objective was gathering sociodemographic data. To evaluate the clinical case, the content was considered paragraph per paragraph and, for each one, the referees issued a report related to the use of technical jargon, the vocabulary used, and clarity and reliability of the information. The referees provided answers by marking whether the assessed items were suitable or not and offered suggestions when they considered pertinent. At the end, they could dwell on their perceptions and considerations about the clinical case.

It is important to stress that the number of respondents was even (ten expert referees) and that there was no tie between agreement and disagreement in the evaluation of the items. Consequently, it was not necessary to add another expert referee to obtain the final definition about the content of the clinical case.

Evaluation of the clinical case construct was carried

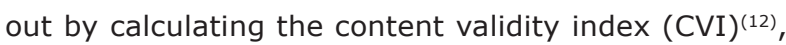
which is the sum of the expert referees in positive agreement divided by the total number of expert referees. The method used was the scale-level CVI based on the average, which corresponds to the sum of CVIs divided by the total number of items. The established acceptance criterion was a CVI $\geq 0.8$.

After validation, the clinical case was adapted into the video script format, with no addition or change in its content. The script included the description of human resources with their characterization (two nurses, two nursing technicians, and the mother), a numbered description of physical resources, and the description of six scenes with orientations related to contexts, camera moves, and lines of the characters.

After that, the clinical case was storyboarded, with the script being used as the source material to produce the video content. The video was filmed in an outpatient facility environment at a public higher education institution, with the presence of six actors and a highfidelity child manikin.

In the post-production step, the recorded material was edited in cooperation with a multimedia material development team. This phase included insertion of visual elements, such as figures and texts related to the illustrations. Six scenes made up the video. After completion of the video production, the material was submitted to evaluation by three expert referees. Subsequently, the video was inserted into a virtual learning environment to be validated by the 25 nursing undergraduate students. They fully filled out a form designed as a Likert scale with five possible scores, each associated with the following statements: I totally agree (5 points), I agree (4 points), I neither agree nor disagree (3 points), I disagree ( 2 points), and I totally disagree
(1 point). These statements were used to evaluate the functioning, usability, efficiency, environment, and audiovisual resources of the produced video.

The interface validation form of the educational video was adapted from studies ${ }^{(13-14)}$ that have developed and used forms with the Likert scale structure as a tool to validate face in educational videos.

The final step was a descriptive data analysis. The answers were systematized using tabulation of the gathered information in a Microsoft Excel spreadsheet.

The present study was approved by the Undergraduate Studies Committee at the educational institution and by the research ethics committee as per Certificate of Presentation for Ethical Evaluation no. 84077418.3.0000.5393 and report no. 2,596,505. All the referees, authors, and undergraduate students read the form and accepted to participate in the study. The actors signed an authorization form allowing image use.

\section{Results}

The first step, the elaboration of the video, resulted in a script and a storyboard with validated content that originated a video version with six scenes, with a total duration of nine minutes and 56 seconds.

The ten expert referees that participated in the content validation of the clinical case were women and nurses, had an average age of 38.4 years, and an average time of 16.5 years since graduation. Regarding their origin, three were from the Brazilian state of Paraná and three from the Brazilian state of São Paulo, and the Brazilian states of Santa Catarina, Paraíba, and Goiás and the Federal District contributed with one nurse each.

During the study execution period, seven referees worked as professors, two were nurses in hospitals that were part of public universities, and one had no employment bond. The average time working on their current job was six years.

For validation, the clinical case was split into nine paragraphs and 36 questions, which covered care to the child and their mother since arrival at the health service until completion of care actions oriented toward the recovery of the child after CPA caused by respiratory failure. Nine questions reached the maximum CVI value of $1.0,14$ obtained a CVI of 0.9 , and 13 got a CVI of 0.8 .

Information clarity, information reliability, and vocabulary reached a CVI of 0.9 . The item technical jargon obtained a CVI of 0.86 . The overall CVI of the clinical case was 0.89 .

There were suggestions for the clinical case content. They addressed adjustments in the sentences to achieve greater information clarity, and all of them were accepted. The third, fourth, and six paragraphs of the clinical case 
were those that obtained the highest number of suggestions for adjustments that could increase the reliability of the data shown and the ease to understand the clinical case.

The validated clinical case was adapted into the script and storyboard formats, which were the basis for production of the educational video.

The final produced video had a title, opening, scenes showing the care delivered to the child with CPA caused by respiratory failure, conclusion, and credits. These characteristics can be seen in Figure 1.
After the shooting, three referees validated the educational video (two nurses that participated in the validation of the clinical case and one communications analyst). Two were women and one was a man, and their ages and time since graduation ranged from 29 to 51 years and seven to 27 years, respectively. They all worked in higher education public institutions, two in the state of São Paulo and one in the state of Paraná. Their time working in the current job varied between 11 months and 31 years.

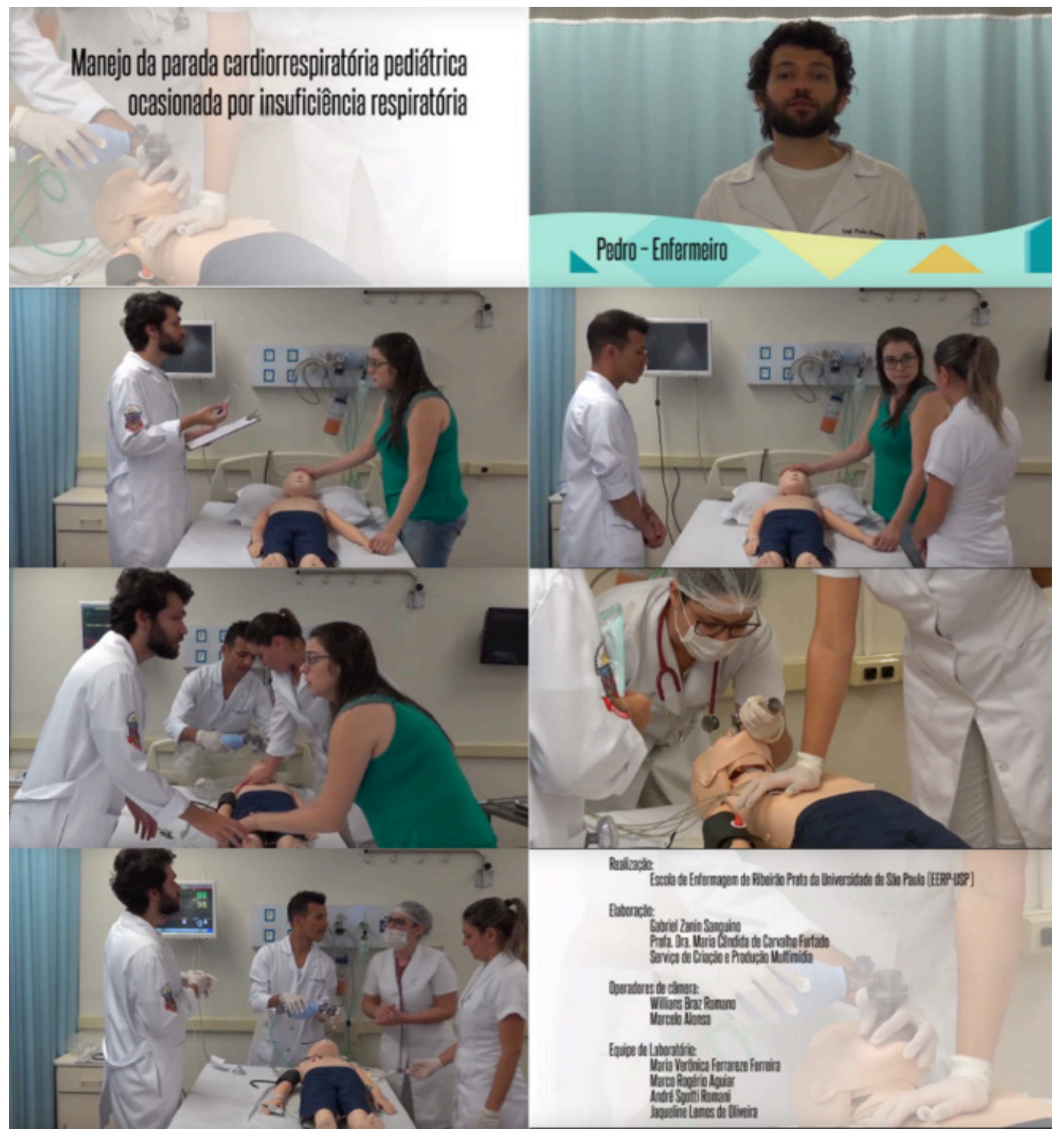

Management of pediatric cardiopulmonary arrest caused by respiratory failure; Pedro - Nurse; Production: Ribeirão Preto College of Nursing at the University of São Paulo; Creation: Gabriel Zanin Sanguino, Professor Maria Cândida de Carvalho Furtado, Ph.D., Multimidia Production and Creation Section; Camera operators: Willians Braz Romano, Marcelo Alonso; Laboratory team: Maria Verônica Ferrareze Ferreira, Marco Rogério Aguiar, André Sgotii Romani, Jaqueline Lemos de Oliveira

*Source: authors' image right

Figure 1 - Edited scenes of the educational video

Functionality, usability, efficiency, environment, and audiovisual resources were the core topics in the set of statements designed to validate the video. The authors opted to adapt forms used by other researchers ${ }^{(13-14)}$, and the statements were presented with five Likert scale-like answers: I totally agree (5 points), I agree (4 points), I neither agree nor disagree (3 points), I disagree ( 2 points), and I totally disagree (1 point).

The statements related to the functionality and usability categories obtained the answers "I totally agree" or "I 
agree". Efficiency and environment received each a "I neither agree nor disagree" statement regarding the distribution of information in the screen and lighting, respectively.

In the audiovisual resources category, one referee neither agreed nor disagreed on two statements that mentioned clarity and the tone of voice of the actors in the video and the possibility of going back to previous scenes when desired.

All the other statements in the validation script obtained "I totally agree" or "I agree" answers.

The validation proposed to the nursing undergraduate students (the video as an educational tool) had the participation of 13 (52\%) students from the nursing undergraduate course and 12 (48\%) from the nursing undergraduate course that gives a license to develop teaching activities. Most of the students ( 23 or $92 \%$ ) were younger than 25 years and had had the care to hospitalized child subject addressed already, which occurred in the third year of the course (14 students or $56 \%)$. When asked whether they had already used some sort of educational technology, 21 (84\%) confirmed that experience. Using the internet to search contents as a support to the training they had in the undergraduate course was unanimity in the examined sample.

The reasons why 34 nursing undergraduate students did not complete their participation in the extension course were not verified in the present study. However, it can be stated that their exclusion did not impact the validation process of the educational material.

The students had access to the video for 30 consecutive days, and they could watch it any time and as many times as they wanted. When this 30-day period was over, they were asked to fill out the video validation script.

Regarding the educational video validation aspects, the answers given by the students are shown in Table 1 . In accordance with the opinion of the referees, most students evaluated the video positively. A small percentage chose the option "I neither agree nor disagree" for 11 items. No student picked the options "I disagree" and/or "I totally disagree".

From these results, it was concluded that the video interface was validated as a material with the potential to contribute to training on the examined subject in the opinion of the consulted expert referees and students.

Table 1 - Distribution of nursing undergraduate students' answers $(n=25)$ related to the educational video according to agreement levels. The items of the validation instrument are listed in the first column. Ribeirão Preto, SP, Brazil, 2018

\begin{tabular}{|c|c|c|c|c|c|c|}
\hline & \multicolumn{2}{|c|}{$\begin{array}{l}\text { I totally } \\
\text { agree }\end{array}$} & \multicolumn{2}{|c|}{ I agree } & \multicolumn{2}{|c|}{$\begin{array}{l}\text { I neither agree nor } \\
\text { disagree }\end{array}$} \\
\hline & $\mathbf{N}$ & $\%$ & $\mathbf{n}$ & $\%$ & $\mathbf{n}$ & $\%$ \\
\hline \multicolumn{7}{|l|}{ Functionality } \\
\hline The video is a tool suitable to the objective it is intended to. & 19 & 76 & 6 & 24 & - & - \\
\hline $\begin{array}{l}\text { The video allows to generate positive results in the teaching-learning process } \\
\text { about pediatric CPA }\end{array}$ & 6 & 60 & 10 & 40 & - & - \\
\hline \multicolumn{7}{|l|}{ Usability } \\
\hline The video is easy to use. & 18 & 72 & 5 & 20 & 2 & 8 \\
\hline $\begin{array}{l}\text { It is easy to learn how care to children with } \mathrm{CPA}^{*} \text { caused by respiratory failure } \\
\text { is provided. }\end{array}$ & 3 & 12 & 17 & 68 & 4 & 16 \\
\hline $\begin{array}{l}\text { The video allows users to easily apply the explored concepts to hospital } \\
\text { practice. }\end{array}$ & 7 & 28 & 15 & 60 & 1 & 4 \\
\hline $\begin{array}{l}\text { The video duration is adequate for users to have greater closeness with its } \\
\text { content. }\end{array}$ & 14 & 56 & 8 & 32 & 2 & 8 \\
\hline The video makes the learning process easier. & 18 & 72 & 7 & 28 & - & - \\
\hline \multicolumn{7}{|l|}{ Efficiency } \\
\hline The video follows a logical sequence. & 17 & 68 & 8 & 32 & - & - \\
\hline $\begin{array}{l}\text { The information is properly distributed over the screen from the spatial point } \\
\text { of view. }\end{array}$ & 15 & 60 & 8 & 32 & 1 & 4 \\
\hline The video refers to a situation that occurs in the hospital setting. & 12 & 28 & 11 & 44 & 1 & 4 \\
\hline \multicolumn{7}{|l|}{ Environment } \\
\hline The laboratory setting did not interfere with the accuracy of the CPA* care. & 9 & 36 & 10 & 40 & 4 & 16 \\
\hline The lighting is adequate to watch the scenes. & 14 & 56 & 10 & 40 & 1 & 4 \\
\hline \multicolumn{7}{|l|}{ Audiovisual resources } \\
\hline The dialogues in the video are delivered efficiently and intelligibly. & 12 & 48 & 9 & 36 & 3 & 12 \\
\hline The voice of the actors is clear and its level is adequate. & 14 & 56 & 8 & 32 & 2 & 8 \\
\hline The number and characterization of characters meet the proposed objective. & 15 & 60 & 9 & 36 & 1 & 4 \\
\hline It is possible to go back to any part of any scene when desired. & 19 & 76 & 6 & 24 & - & - \\
\hline The number of scenes is compatible with the video duration. & 17 & 68 & 8 & 32 & - & - \\
\hline
\end{tabular}

${ }^{*} \mathrm{CPA}=$ Cardiopulmonary arrest 


\section{Discussion}

The teaching of pediatric emergencies, and specifically of the management of pediatric CPA, has important gaps for nursing professionals related to the theoretical and scientific knowledge to efficiently work in face of this emergency(15-16).

The literature addresses CPA approach and use of active and/or educational methodologies to be applied to health professionals with studies on the use of these tools to teach the subject to medical students ${ }^{(17-18)}$, hence the importance of the present study, which is focused on the learning process of nursing students.

It is understood that, with the change in the profile of students at higher education institutions, educational approaches must meet their needs and expectations. The production of multimedia material is a tool that strengthens the teaching-learning process $^{(19)}$.

The use of digital information and communications technologies has become increasingly common in the academic universe, especially in the undergraduate level, and the training of nurses has stood out in this scenario. A study ${ }^{(19)}$ showed that applying this type of technology positively impacts the population's health.

The development of educational videos is a practice that can contribute to transforming knowledge. This type of material leads to autonomy and independence, empowering students during the process of getting knowledge about varied subjects ${ }^{(8)}$.

Educational videos, an example of active technological methodologies, are digital tools that correspond to the recording of images and sounds with posterior reproduction and have the potential to stimulate the people who watch them and hold their attention(13).

With an increasing prominence in the academic context, the production of educational videos has been a research subject whose growing importance in the nursing area is expressed by the existence of studies that have addressed the development and validation of this type of material to help in the learning process of several subjects $^{(14,20)}$.

It is important to emphasize the relevance of using a methodological framework ${ }^{(10)}$ in the process of creating the material that will substantiate the educational video, a practice carried out by the authors of the present study(21-22).

The elaboration of a clinical case for validation before the preparation of the storyboard and the writing of the script was an approach different from that used in a similar study ${ }^{(14)}$. This characteristic is explained by the fact that the present study is part of a more comprehensive research project that concomitantly investigates other educational approaches. The clinical case was a guiding material for other learning tools too.
It was identified that making the video script available in the validation by expert referees was a fundamental element in the development of an educational video. However, the approach used in the present study (proposing a clinical case that, after validation, was adapted into the script format) allowed a higher accuracy in the preparation of the material used to create the scenes to be filmed.

The educational video development process was facilitated by the conditions offered by the educational institution to which the study was linked. It is understood that the availability of physical and human resources for the creation of this type of material is fundamental for making a satisfactory product ${ }^{(23)}$. It is important to emphasize that support from educational institutions to develop materials such as that described in the present study motivates and encourages professionals to carry out that practice more often ${ }^{(19)}$.

The result is in agreement with the recommendation that the duration of educational videos does not exceed 15 minutes(24), which has been followed in other studies ${ }^{(14,22,25)}$.

Using well-defined criteria to select referees is an indispensable practice and directly impacted the development of the present study ${ }^{(26)}$. It must be stressed that two referees participated in the validation of both the clinical case and the video, which allowed to monitor the developed material and provided greater clarity in the steps for the elaboration of the final product.

Making the material available for 30 days in the process of evaluation by nursing undergraduate students allowed them to access the video as many times as they considered necessary to fill out the validation form online subsequently.

The educational video validation process carried out by referees and nursing undergraduate students was satisfactory, since there was a predominance of positive evaluations for the examined material.

Production of videos and their use for academic purposes allow a greater engagement of students in the teaching-learning process, encourages them to develop their autonomy, and have the potential to immediately transform knowledge ${ }^{(8)}$.

In the training of nursing professionals, the use of digital technologies can be one of the means to provide this workforce with resources and decisively meet the demands that emerge in an increasingly digital world(27). The author of the mentioned study emphasizes that the maturity of the digital transformation in the health area is an opportunity to qualify the nursing work and points to the progress in skills inherent in the digital field as a challenge to this health area ${ }^{(27)}$. It is understood that the present study showed that this path can be initiated during the training of future professionals. 
A limitation of the study was the fact that the questions involving the changes in the knowledge of nursing undergraduate students were not deeply examined. The focus of the investigation was the face and content of the produced material.

\section{Conclusion}

An educational video on pediatric CPA caused by respiratory failure was made and validated by expert referees and nursing undergraduate students. It was considered that the final version of the educational material is fit to be used with students in nursing undergraduate courses. The present study contributed to the area by making an innovative digital tool available to teaching practices about the management of pediatric CPA caused by respiratory failure oriented toward nursing undergraduate students.

In a context with constant technological evolution and academic needs that promote the building of knowledge according to the demands of the students, the scientific offer of methodological aspects related to the development and validation of technological and digital learning objects encourages an education compatible with the current academic reality.

\section{References}

1. Santos EB. Dimensions of care and social practices in child cardiac arrest and cardiopulmonary ressuscitation: nurses role of the pediatric intensive care unit of a public hospital in Vitória da Conquista/BA. Protest Rev. [Internet]. 2015 [cited Aug 27, 2019];(37):145-51. Available from: http://ism.edu.br/periodicos/index.php/ nepp/article/view/2649

2. Vega RM, Kaur H, Edemekong PF. Cardiopulmonary Arrest In Children. [Internet]. 2020 [cited Aug 27, 2020]. Available from: https://www.ncbi.nlm.nih.gov/books/ NBK436018/

3. Haegdorens F, Van Bogaert P, De Meester K, Monsieurs KG. The impact of nurse staffing levels and nurse's education on patient mortality in medical and surgical wards: an observational multicentre study. BMC Health Serv Res. 2019;19(1):864. doi: 10.1186/s12913-019-4688-7

4. Martín-Gutíerrez J, Mora CE, Añorbe-Díaz B, GonzálezMarrero A. Virtual Technologies Trends in Education. EURASIA J Math Sci Tech Ed. 2017;13(2):469-86. doi: 10.12973/eurasia.2017.00626a

5. Prensky M. Digital natives, digital immigrants. On the horizon. [Internet]. 2001 [cited 27 Aug, 2019];9(5):1-6. Available from: https://www.marcprensky.com/writing/ Prensky\%20-\%20Digital\%20Natives,\%20Digital\%20 Immigrants\%20-\%20Part1.pdf
6. Bublitz S, Guido LA, Kirchhof RS, Neves ET, Lopes LFD. Sociodemographic and academic profile of nursing students of four Brazilian institutions. Rev Gaúcha Enferm. 2015;36(1):78-83. doi: http://dx.doi.org/10.1590/19831447.2015.01.48836

7. Diesel A, Baldez ALS, Martins SN. Active teaching methodologies principles: a theoretical approach. Rev Thema. 2017;14(1):268-88. doi: 10.15536/ thema.14.2017.268-288.404

8. Bahar A, Arslan M, Gokgoz N, Ak H, Kaya H. Do parenteral medication administration skills of nursing students increase with educational videos materials?. Int J Caring Sci. [Internet]. 2017 [cited Aug 27, 2019];10(3):1514-25. Available from: https://www. internationaljournalofcaringsciences.org/docs/45_1bahar_original_10_3.pdf

9. Leite SS, Áfio ACE, Carvalho LV, Silva JM, Almeida PC, Pagliuca LMF. Construction and validation of an Educational Content Validation Instrument in Health. Rev Bras Enferm. 2018;71(Suppl4):1635-41. doi: 10.1590/00347167-2017-0648

10. Fleming SE, Reynolds J, Wallace B. Lights... camera...action! A guide for creating a DVD/Vídeo. Nurse Educator. 2009;34(3):118-21. doi: 10.1097/ NNE.0b013e3181a0270e

11. Fehring RJ. Methods to validate nursing diagnosis. Heart Lung. [Internet]. 1987 [cited Aug 27, 2019];16(6):625-9. Available from: https://pdfs.semanticscholar.org/11f7/ d8b02e02681433695c9e1724bd66c4d98636.pdf

12. Yusoff MSB. ABC of content validation and content validity index calculation. Education in Medicine Journal. 2019;11(2):49-54. doi: 10.21315/eimj2019.11.2.6

13. Ferreira MVF, Godoy S, Góes FSN, Rossini FP, Andrade D. Lights, câmera and action in the implementation of central venous catheter dressing. Rev. Latino-Am. Enfermagem. 2015;23(6):1181-6. doi: 10.1590/01041169.0711 .2664

14. Campoy LT, Rabeh SAN, Castro FFS, Nogueira PC, Tercario CAS. Bowel rehabilitation of individuals with spinal cord injury: vídeo production. Rev Bras Enferm. 2018;71(5):2376-82. doi: 10.1590/0034-7167-20170283

15. Santos EB. Cardiopulmonary arrest and resuscitation in children: performance of the nursing staff of the Intensive Pediatric Care Unit in a public hospital in Vitoria da Conquista in Bahia. Id On Line Rev Mult Psic. 2017;11(39):410-31. doi: 10.14295/idonline.v12i39.999 16. Rajeswaran L, Cox M, Moeng S, Tsima BM. Assessment of nurses' cardiopulmonary resuscitation knowledge and skills within three district hospitals in Botswana. Afr J Prim Health Care Fam Med. 2018;10(1):1-6. doi: 10.4102/ phcfm.v10i1.1633 
17. McCoy CE, Rahman A, Rendon JC, Anderson CL, Langdorf MI, Lotfipour S, et al. Randomized controlled trial of simulation vs. standard training for teaching medical students high-quality cardiopulmonary resuscitation. West J Emerg Med. 2019;20(1):15-22. doi: $10.5811 \% 2 F w e s t j e m .2018 .11 .39040$

18. Drummond D, Arnaud C, Thouvenin G, Guedj R, Grimprel E, Duguet $A$, et al. An innovative pedagogic course combining video and simulation to teach medical students about pediatric cardiopulmonary arrest: a prospective controlled study. Eur J Pediatr. 2016;175(6):767-74. doi: 10.1007/s00431-016-2702-1

19. Kumar S, Daniel BK. Integration of learning technologies into teaching within Fijian Polytechnic Institutions. Int J Educ Technol High Educ. 2016;13(1):117. doi: 10.1186/s41239-016-0036-8

20. Aceto G, Persico V, Pescapé A. The role of Information and Communication Technologies in healthcare: taxonomies, perspectives, and challenges. J Netw Comput Appl. 2018;107:125-54. doi: 10.1016/j.jnca.2018.02.008 21. Silva NF, Silva NCM, Ribeiro VS, Iunes DH, Carvalho EC. Construction and validation of an educational video on foot reflexology. Rev Eletr Enferm. 2017;19:a48. doi: 10.5216/ree.v19.44324

22. Lima MB, Rebouças CBA, Castro RCMB, Cipriano MAB, Cardoso MVLML, Almeida PC. Construction and validation of educational vídeo for the guidance of parents of children regarding clean intermittent catheterization. Rev Esc Enferm USP. 2017;51:e03273. doi: 10.1590/ s1980-220x2016005603273

23. Claro M, Salinas Á, Cabello-Hutt T, San Martín E, Preiss DD, Valenzuela $S$, Jara I. Teaching in a Digital Environment (TIDE): defining and measuring teachers' capacity to develop students' digital information and communication skills. Comput Educ. 2018;121:162-74. doi: 10.1016/j.compedu.2018.03.001

24. Hartsell T, Yuen S. Video streaming in online learning. AACE J. [Internet]. 2006 [cited Aug 27, 2019];14(1):3143. Available from: https://www.learntechlib.org/ primary/p/6152/

25. Dalmolin A, Girardon-Perlini NMO, Coppetti LC, Rossato GC, Gomes JS, Silva MEN. Educational video as a healthcare education resource for people with colostomy and their families. Rev Gaucha Enferm. 2016;37:e68373. doi: 10.1590/1983-1447.2016.esp.68373

26. Melo RP, Moreira RP, Fontenele FC, Aguiar ASC, Joventino ES, Carvalho EC. Criteria for selection of experts for validation studies of nursing phenomena. Rev RENE. [Internet]. 2011 [cited Aug 27, 2019];12(2):424-31. Available from: http://periodicos.ufc.br/rene/article/ view/4254/3285

27. Lapão LV. The Nursing of the Future: combining Digital Health and the Leadership of Nurses. Rev. LatinoAm. Enfermagem. 2020;28:e3338. doi: http://dx.doi. org/10.1590/1518-8345.0000-3338

\section{Authors' Contribution:}

Study concept and design: Gabriel Zanin Sanguino, Maria Cândida de Carvalho Furtado. Obtaining data: Gabriel Zanin Sanguino. Data analysis and interpretation: Gabriel Zanin Sanguino, Maria Cândida de Carvalho Furtado. Statistical analysis: Gabriel Zanin Sanguino, Maria Cândida de Carvalho Furtado. Drafting the manuscript: Gabriel Zanin Sanguino, Maria Cândida de Carvalho Furtado, Simone de Godoy, Jéssica Batistela Vicente, Jacqueline Rodrigues da Silva. Critical review of the manuscript as to its relevant intellectual content: Gabriel Zanin Sanguino, Maria Cândida de Carvalho Furtado, Simone de Godoy, Jéssica Batistela Vicente, Jacqueline Rodrigues da Silva.

All authors approved the final version of the text.

Conflict of interest: the authors have declared that there is no conflict of interest.
Corresponding author:

Gabriel Zanin Sanguino

E-mail: gzanins@gmail.com

(D) https://orcid.org/0000-0002-3273-5496
Received: Aug 27th 2019 Accepted: Aug $6^{\text {th }} 2020$

Associate Editor: Maria Lúcia Zanetti

Copyright $\odot 2021$ Revista Latino-Americana de Enfermagem This is an Open Access article distributed under the terms of the Creative Commons (CC BY).

This license lets others distribute, remix, tweak, and build upon your work, even commercially, as long as they credit you for the original creation. This is the most accommodating of licenses offered. Recommended for maximum dissemination and use of licensed materials. 